\title{
Update on the clinical utility of sildenafil in the treatment of pulmonary arterial hypertension
}

\author{
This article was published in the following Dove Press journal: \\ Drug Design, Development and Therapy \\ 5 May 2010 \\ Number of times this article has been viewed
}

\author{
Gautam V Ramani \\ Myung H Park \\ University of Maryland, Baltimore, \\ MD, USA
}

Correspondence: Gautam Ramani Assistant Professor of Medicine, 22 S. Greene Street, S3B08, Baltimore, MD 21201 , USA

$\mathrm{Tel}+\mid$ 4l0-328-2613

Fax + I 4I0-328-1048

Email gramani@medicine.umaryland.edu

\begin{abstract}
Sildenafil is an orally administered phosphodiesterase type 5 inhibitor that is approved for the treatment of pulmonary arterial hypertension (PAH). The hemodynamic effects of sildenafil are mitigated primarily via potentiating the effects of endogenous nitric oxide, leading to smooth muscle cell relaxation and reductions in pulmonary arterial pressures and pulmonary vascular resistance. When added to standard background therapy in patients with idiopathic or associated PAH from congenital heart disease, anorexigen use, or connective tissue disease, sildenafil treatment results in improved exercise capacity as measured by 6 minute walk distance, improved hemodynamics, and favorable changes in quality of life. Sildenafil use is contraindicated with concomitant nitrate administration, and caution should be exercised when used in combination with antihypertensive agents due to risks of precipitating hypotension. Side effects are generally mild, and include flushing, headaches, and epistaxis. The combination of sildenafil with intravenous epoprostenol is safe and well tolerated, and further improves exercise capacity. Sildenafil is approved only for treatment of PAH, and although emerging data suggest a potential role in treating other types of pulmonary hypertension, larger trials are required to confirm these findings.
\end{abstract}

Keywords: sildenafil, pulmonary arterial hypertension, phosphodiesterase type 5 inhibitor

\section{Introduction}

Pulmonary arterial hypertension (PAH) is a life-threatening disorder characterized by progressive remodeling of the pulmonary vasculature, leading to a rise in pulmonary arterial pressures and pulmonary vascular resistance that often culminates in right ventricular (RV) failure. Despite regional variations in disease epidemiology, a recent European registry estimates the prevalence PAH at approximately 15.0 cases/million. ${ }^{1}$ Worldwide, prevalence of PAH is likely to rise, given increased awareness among physicians, salutatory effects of treatment, increased use of amphetamine stimulants, recognition of schistosomiasis as a common etiologic agent in certain regions, and greater appreciation for the role of hemoglobinopathies in PAH. ${ }^{2}$ Prior to the widespread use of disease-specific pharmacotherapy, mortality was high, with a median survival of $50 \%$ at 2.8 years. $^{3}$ Although few randomized trials have been designed to assess survival, observational data suggest improved outcome in the pharmacotherapy era, with 2-year survival estimated at $89 \%{ }^{4}$

Treatment of PAH has evolved dramatically over the past 15 years. Prior to 1996, treatment was focused upon symptom control which included management of RV failure with diuretics and digoxin, supplemental oxygen therapy to correct hypoxemia, and judicious use of calcium channel blockers. The recognition that PAH progression 
was characterized by vascular remodeling and an imbalance between proliferative and anti-inflammatory mediators led to the identification of the importance of endothelin, prostacyclin, and nitric oxide (NO) in disease initiation and progression (Figure 1). These key pathways currently serve as targets for disease-specific treatment modalities that have revolutionized PAH management, by improving functional capacity, hemodynamics, and patient well being. ${ }^{5}$ In PAH, the ideal pharmacologic agents should facilitate vasorelaxation and restoration of the balance between apoptosis and cellular proliferation, ultimately preserving RV function and delaying the onset of right heart failure. ${ }^{6}$

Sildenafil, an orally administered a phosphodiesterase type 5 (PDE-5) inhibitor, targets the NO pathway. The drug was first approved for the treatment of erectile dysfunction in 1998, and approved for treatment of PAH in 2005. ${ }^{7,8}$ This review will summarize the mechanisms behind the therapeutic efficacy of sildenafil, review the role for sildenafil in the treatment of PAH, and highlight emerging roles for sildenafil in heart failure and other cardiopulmonary conditions.

\section{Sildenafil background and mechanisms of action}

The effects of sildenafil in treating both erectile dysfunction and PAH are accomplished by enhancing the downstream effects of NO mediated vasorelaxation (Figure 2). NO is a labile gas produced by NO synthases located in the vascular endothelial and airway epithelial cells that freely diffuses

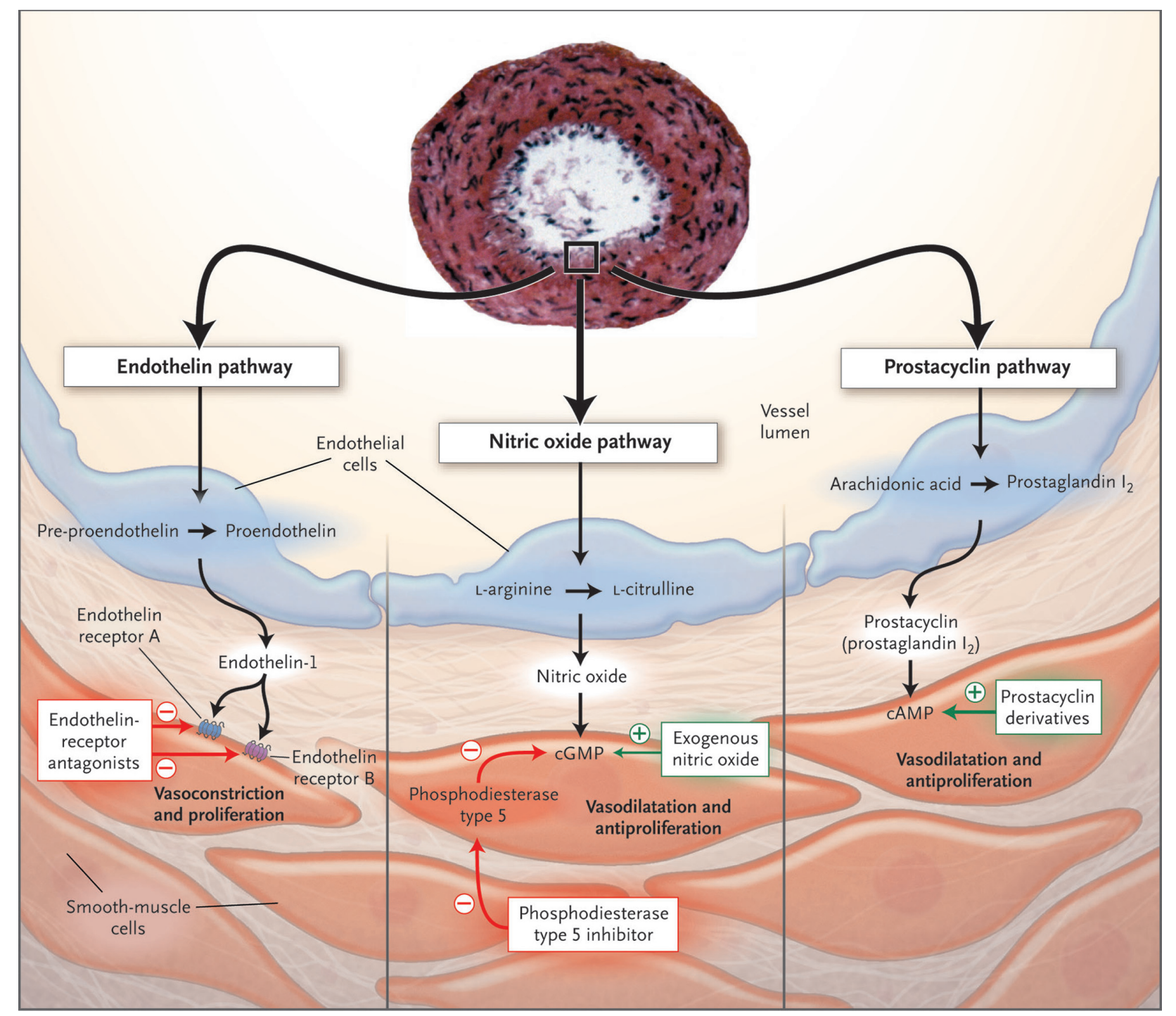

Figure I Cellular mechanisms of sildenafil actions.

Reproduced with permission from Humbert M, Sitbon O, Simonneau G. Treatment of pulmonary arterial hypertension. N Engl J Med. 2004;35I:I425-1436. ${ }^{68}$ Copyright $\odot$ 2004 Massachusetts Medical Society. All rights reserved.

Abbreviation: cGMP, cyclic guanosine monophosphate. 


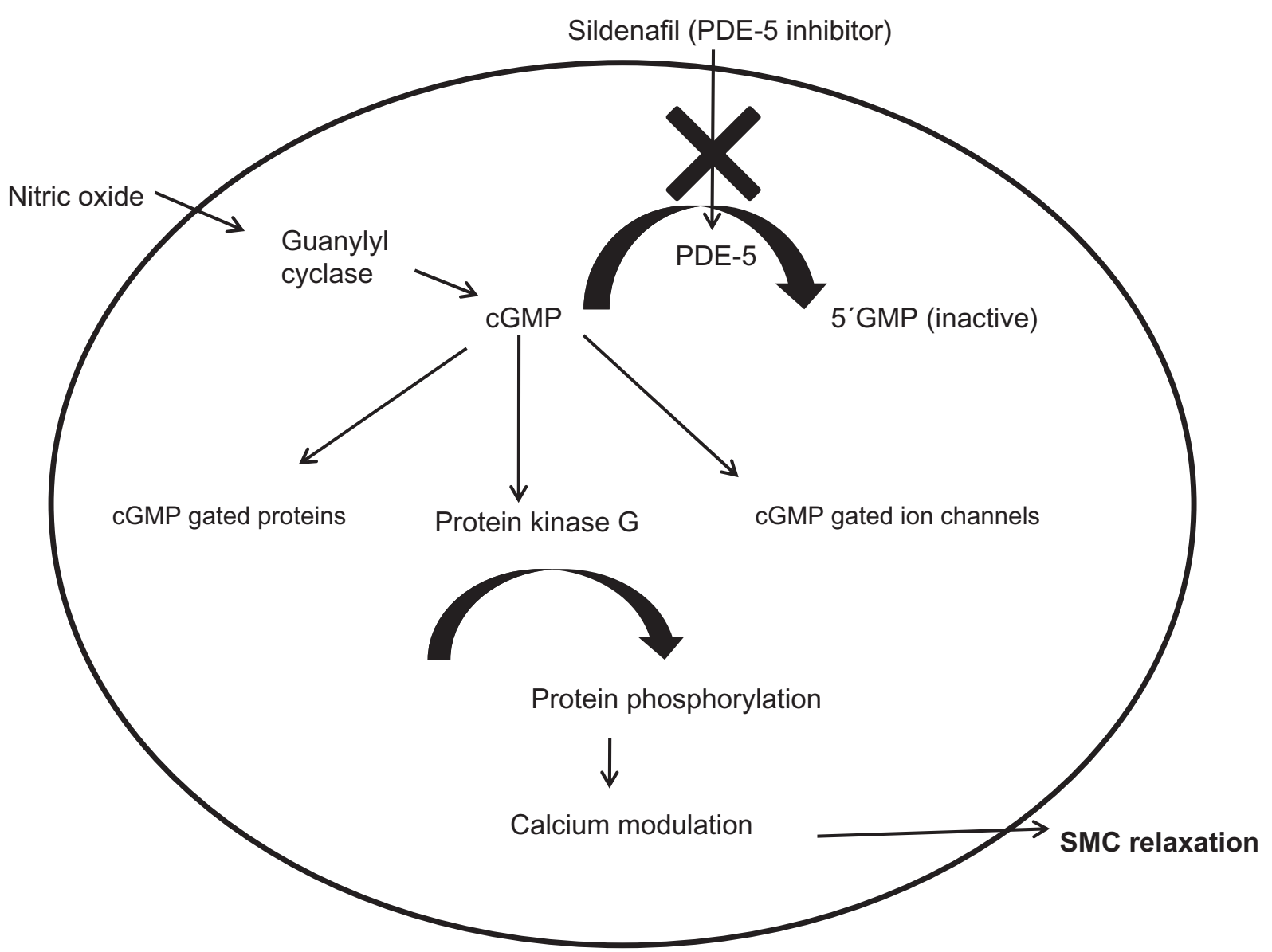

Figure 2 Endothelial cell.

Abbreviations: cGMP, cyclic guanosine monophosphate; PDE, phosphodiesterase; SMC, smooth muscle cell.

across capillary membranes. On a cellular level, NO stimulates conversion of guanosine triphosphate (GTP) to cyclic guanosine monophosphate (cGMP). Intracellular cGMP has multiple effects on cellular physiology mediated by activation of protein kinases, specifically regulation of ion channels and alteration of intracellular cyclic nucleotide concentrations. ${ }^{9}$ From a physiological standpoint, NO stimulates dilatation of vascular smooth muscle at both the arterial and venous levels. Antiproliferative effects of NO have been well described. ${ }^{10,11}$ The importance of NO in PAH is magnified because PAH is intrinsically associated with reduced endogenous $\mathrm{NO}$ production. The ability to maintain NO production in the setting of hypoxia may play a role in delaying the onset of pulmonary hypertension (PH). ${ }^{12,13}$

Reduced levels of cGMP have deleterious effects, leading to altered calcium handling and subsequent vasoconstriction and smooth muscle cell proliferation. ${ }^{6}, 14$ cGMP levels are regulated by PDE enzymes. Currently, 11 different families of PDE isoenzymes have been identified, which vary in substrate selectivity, tissue location, and mechanism of action
(Table 1). PDE-5 has been the focus for PAH because the PDE-5 enzyme is highly expressed in lung tissue compared to other vascular beds, with minimal expression in the systemic circulation. ${ }^{15,16}$ PDE-5 expression is upregulated in $\mathrm{PAH}$, leading to increased metabolism of NO-derived cGMP. For these reasons, inhibition of PDE-5 was hypothesized to serve as a viable target to enhance NO-mediated physiologic effects. ${ }^{17}$ The utility of PDE-5 inhibition in PAH was first demonstrated in 1991, when investigators successfully used the PDE-5 inhibitor zaprinast to mitigate alveolar induced hypoxia. ${ }^{18}$ Sildenafil, the first commercially available oral PDE-5 inhibitor, was studied in 2001 and demonstrated to prevent development of $\mathrm{PH}$ in hypoxic mouse models. ${ }^{19}$

Targeting of the NO pathway with exogenous oral nitrates is limited by the rapid development of tachyphylaxis. ${ }^{20}$ Treatment with PDE-5 inhibitors indirectly modulates the NO pathway by acting on a downstream site, thereby obviating this problem.

Additional pleotropic mechanisms may contribute to the beneficial effects of sildenafil in PAH. Antioxidant properties 
Table I Phosphodiesterase isoenzymes

\begin{tabular}{lll}
\hline PDE type & Function & Primary distribution \\
\hline $\mathrm{I}$ & $\mathrm{Ca}^{2+}$ modulation; smooth cell proliferation & Smooth muscle cells; proliferating tissue \\
2 & $\mathrm{Ca}^{2+}$ channel regulation; aldosterone secretion & Brain, adrenal glands \\
3 & Cardiac contractility & Cardiac myocytes, vascular smooth muscle \\
4 & Immunological and inflammatory signaling & Neural and endocrine tissue \\
5 & Penile erection; regulation of airway smooth muscle cells & Penile tissue, airway smooth muscle cells \\
6 & Eyesight & Photoreceptor cells in retina \\
7 & Regulation of T lymphocytes & T lymphocytes and skeletal muscle tissue \\
8 & T cell activation & Testis and thyroid gland \\
9 & Unclear & Spleen, intestine, heart, brain \\
10 & Unclear & Widely expressed in all tissue beds \\
II & Sperm capacitation & Vascular smooth muscle, penis, cardiac myocytes \\
\hline
\end{tabular}

Adapted from Barst. ${ }^{69}$

have been described in other tissue beds..$^{21,22}$ Controversy exists about the presence of a direct RV inotropic effect of sildenafil. The hypertrophied RV demonstrates increased tissue expression of PDE-5. ${ }^{23}$ In healthy individuals, PDE-5 is expressed in the coronary arteries, but is not typically found in cardiac myocytes. One study comparing sildenafil to inhaled $\mathrm{NO}$ (iNO) demonstrated comparable reductions in PA pressures and pulmonary vascular resistance (PVR), but increased cardiac index (CI) was seen only with sildenafil treatment, consistent with an inotropic effect. ${ }^{24}$ However, other investigators, examining load-independent measures of myocardial performance, found no changes in systolic or diastolic function with sildenafil treatment. ${ }^{25}$ Circulating endothelial progenitor cells are reduced in idiopathic PAH and congenital PAH, and treatment with sildenafil has been shown to increase these cells to levels consistently higher than other PAH therapies. ${ }^{26}$ Sildenafil also inhibits PDE-1, which is expressed in low levels in the pulmonary circulation under baseline conditions but is upregulated in the disease state. ${ }^{27}$ The clinical significance of these findings remains uncertain. Ultimately, modulation of cGMP leads to improved calcium handling and restoration of the balance between apoptosis and smooth cell proliferation, resulting in vascular reverse remodeling.

\section{Drug pharmacokinetics and interactions}

Maximum plasma concentrations of sildenafil dosed at the Food and Drug Administration (FDA) approved schedule of $20 \mathrm{mg} 3$ times daily are achieved 1 hour after administration, with a half-life of approximately 4 hours. Bioavailability is approximately $40 \%$, which is reduced to $29 \%$ following a large meal. ${ }^{28}$ In the elderly (age $>65$ years) the clearance of sildenafil is impaired, with increased drug half-life and maximum serum concentrations. ${ }^{29}$ The pharmacokinetics of sildenafil are not altered in the setting of mild to moderate renal insufficiency. Although serum levels can rise in severe impairment, dosing changes are usually not required.$^{29}$ Similarly, in patients with Child's A or B cirrhosis, despite increased drug levels, dose adjustments are rarely necessary. ${ }^{29}$

Sildenafil is metabolized primarily by the hepatic cytochrome P450 (CYP) 3A4 enzymes and to a lesser extent by CYP2C9 enzymes. The primary metabolite, $\mathrm{N}$-desmethylsildenafil, maintains PDE-5 specificity, but with reduced potency, and plasma levels approaching $40 \%$ of primary compound. ${ }^{28}$ Careful monitoring is advisable with coadministration with CYP3A4 inducers (carbamazepine, phenytoin, nevirapine), as sildenafil dose increases may be necessary. Bosentan is an inducer of the CYP3A4 pathway, and the use of these drugs in combination will be discussed later in this review. Sildenafil is currently listed by the FDA as a category B drug in pregnancy. ${ }^{30}$ There are only small case series examining drug safety in pregnancy, and caution is advised in this regard. ${ }^{31}$

\section{Drug side effects}

Review of the pivotal SUPER 1 study demonstrate that the most frequent placebo subtracted side effects were epistaxis $(8 \%)$, headache $(7 \%)$, and flushing $(6 \%) .{ }^{8}$ There was a dose-dependent increase in the incidence of drugrelated side effects, including flushing, headache, and blurry vision. No significant laboratory abnormalities were identified. Retinal hemorrhage occurred more commonly in the sildenafil-treated group ( $1.4 \%$ vs $0 \%)$, but most patients who developed this condition were taking oral anticoagulants. Because of a shared and common pathway of increased NO-mediated effects, concomitant administration with oral 
nitrate medications can potentiate the effects of either agent, and their use together is contraindicated. ${ }^{32}$ Administration of sildenafil to patients taking nitrate medications can produce dramatic reductions in blood pressure (systolic blood pressure drop in excess of $50 \mathrm{mmHg}$ ) and syncope. ${ }^{33}$ Sildenafil should not be administered to patients who have taken any oral or sublingual preparation within the previous 24 hours. While larger doses of sildenafil have been associated with significant reduction in systolic blood pressure approaching $10 \mathrm{mmHg}$, the FDA-approved dose of $20 \mathrm{mg}$ by mouth 3 times daily has not been shown to significantly affect blood pressure. ${ }^{34}$ Blurry vision has been described at higher doses, primarily due to minor inhibition of PDE-6 located in the eyes.

Nonarteritic anterior ischemic optic neuropathy (NAION) is a common cause of acute optic neuropathy in the elderly. Anecdotal reports and cases series suggested increased risks of NAION in sildenafil-treated patients. However, pooled data from clinical trials of all three commercially available PDE-5 inhibitors (sildenafil, tadalafil, vardenafil) suggested no increased risk of NAION. ${ }^{35}$ Patients at highest risk for development of NAION are those who have previously suffered NAION in one eye, and those with other risk factors for vascular disease, including diabetes mellitus. Although these findings are reassuring to health care providers, it remains advisable to monitor for visual changes, and to seek prompt medical attention for sudden vision loss. Uncommon drug effects, including a case report of thrombocytopenia, have been described. ${ }^{36}$

\section{Clinical trial experience}

The first case report demonstrating a clinical benefit of sildenafil in PAH was published in $2000 .{ }^{37}$ Earlier work had suggested utility of sildenafil in other cardiopulmonary conditions, including weaning mechanically ventilated patients with iNO-dependent respiratory failure. ${ }^{38}$ Building on this promising early experience, single-center studies were completed that suggested significant clinical efficacy and both functional and hemodynamic improvement in PAH. ${ }^{39}$ Taken together these studies suggested that sildenafil, in a dosedependent manner, had durable and sustained pulmonary vasodilator effects.

The SUPER-1 trial (Sildenafil Use in PUlmonary hypERtension) commenced enrollment in 2002, and randomized patients with $\mathrm{PAH}$ to treatment with either sildenafil (20 mg, $40 \mathrm{mg}, 80 \mathrm{mg}) 3$ times daily or placebo. ${ }^{8}$ The primary endpoint in this study, similar to most PAH trials, was assessing exercise capacity as measured by changes in 6 minute walk distance (6MWD) at 12 weeks. Secondary endpoints included changes in invasive hemodynamic parameters, BORG dyspnea score, clinical worsening, and health related quality of life (QoL). The study was restricted to patients with idiopathic $\mathrm{PAH}$, and acquired $\mathrm{PAH}$ from connective tissue disease (CTD), congenital heart disease (CHD), or previous anorixegen use, and composed of patients with moderate disease severity (Table 2), who were predominantly World Health Organization (WHO) functional class II (39\%) and III (58\%), and had a mean 6MWD of $344 \mathrm{~m}$. The mean age of patients included in the study was 49 years, and approximately three-fourths of patients were female.

After 12 weeks, the mean placebo corrected increase in 6MWD was $45 \mathrm{~m}$. A trend towards improved exercise capacity was detected as early as 4 weeks. Sildenafil treatment was associated with a statistically significant number of patients who improved by at least one functional class $(21 \%$, $P=0.003)$. There were no significant differences between the sildenafil- and placebo-treated groups in BORG dyspnea score, or the incidence of clinical worsening, defined as a combined endpoint of death, lung transplantation, hospitalization for PAH or need to institute combination therapy.

Patients who completed the study were eligible to enroll in an extension study, where doses were uptitrated to $80 \mathrm{mg}$ by mouth 3 times daily. The results of the extension study have not yet been published. Subgroup analysis from the SUPER-1 study in 84 patients with CTD demonstrated that the drug was equally safe and efficacious this patient population. ${ }^{40}$ Analysis of QoL measures demonstrated that treatment with sildenafil significantly improved physical functioning, and general health, vitality, and well-being.

Based primarily upon the results of SUPER-1 study, in 2005, sildenafil was approved for the treatment of PAH in both the United States and Europe at the $20 \mathrm{mg} 3$ times daily dose. Although there were no differences in 6MWD between the three doses during the pivotal trial period, dose-dependent changes in hemodynamic parameters, particularly mean pulmonary arterial pressure (mPAP) and PVR, were identified.

Table 2 WHO functional classification of pulmonary hypertension

\begin{tabular}{ll}
\hline Classification & Symptoms \\
\hline Class I & $\begin{array}{l}\text { No limitations in daily physical activities. No } \\
\text { symptoms of dyspnea with routine exertion }\end{array}$ \\
Class II & $\begin{array}{l}\text { Mild symptoms with exertion, including dyspnea and } \\
\text { fatigue. No symptoms at rest }\end{array}$ \\
Class III & $\begin{array}{l}\text { Moderate dyspnea with routine activities and } \\
\text { activities of daily living. No symptoms at rest }\end{array}$ \\
Class IV & $\begin{array}{l}\text { Inability to perform even minimal activities. Signs } \\
\text { and symptoms of right heart failure may be present. } \\
\end{array}$ \\
& Dyspnea present at rest
\end{tabular}

Adapted from McLaughlin and McGoon. ${ }^{70}$ 
Additional small studies have suggested safety and efficacy of higher doses of sildenafil, but obtaining insurance approval for these higher doses remains challenging. ${ }^{41}$

\section{Clinical use of sildenafil}

Sildenafil is indicated in patients with mild to moderate pulmonary hypertension (WHO FC II-III). ${ }^{42}$ There are no data to support treatment in asymptomatic individuals, and the drug should not be used as a first-line agent in markedly symptomatic patients (WHO FC IV, 6MWD < $100 \mathrm{~m}$ ). When considering initiating treatment with sildenafil, the physician must carefully examine the existing medication list, monitor for drugs that may potentiate an interaction (alpha-blockers, nitrates) and assess for systemic hypotension that may worsen with treatment.

Currently, sildenafil is one of nine FDA-approved pharmacologic therapies for PAH. These include treatments involving continuous infusions, using hand-held inhaled devices, and pills. Before choosing an agent, several factors should be assessed, including disease severity, existing comorbidities, patient compliance, family support, and drug side effects-interactions. Regardless of chosen pharmacotherapy, regular follow up, and surveillance for disease progression and development of RV failure are critical in disease management.

There are very few head to head trials comparing different agents. One small study comparing high dose sildenafil (dose titration to $50 \mathrm{mg} 3$ times daily) to bosentan dosed at $125 \mathrm{mg}$ by mouth twice daily, demonstrated no significant change in the primary endpoint (RV mass), or secondary endpoints, including 6MWD and B-type natriuretic peptide levels. ${ }^{43}$ In patient with WHO FC II-III disease, most experts recommend initial therapy with an oral agent with careful follow up for disease progression. ${ }^{42}$ These recommendations stem primarily from the efficacy of the oral agents, coupled with desire to avoid potential infectious complications with continuous infusion therapy and the cumbersome nature of inhaled therapy, which requires 4 to 9 treatments daily. An advantage of PDE-5 inhibitor over the endothelin receptor antagonists ambrisentan and bosentan, is that therapy with PDE-5 inhibitors does not require safety monitoring with monthly liver function tests.

\section{Sildenafil in other acquired PAH}

Smaller studies have been completed in patients who were not eligible for the larger scale phase III clinical trials. Patients with end-stage liver disease are susceptible to development of portopulmonary hypertension, which, if untreated, is a contraindication for liver transplantation. While epoprostenol has long been the gold standard for treatment of portopulmonary hypertension, smaller studies suggest that in milder cases, sildenafil treatment can be safely used as a bridge to liver transplantation. ${ }^{44}$

\section{Combination therapy}

The rational for combination therapy stems from using different classes of medications target the disease from multiple mechanisms. As a general rule, efficacy should be maximized, while minimizing drug toxicity. Despite the number of agents available, limited published data are available to guide decision making in this regard. Given the costs associated with PAH therapy and potential for drug interactions and side effects, caution is advised when attempting combination therapy. The largest clinical trial evaluating combination therapy studied adding sildenafil, at doses ranging from $40 \mathrm{mg} 3$ times daily to $80 \mathrm{mg} 3$ times daily, to patients on stable doses of intravenous epoprostenol. ${ }^{45}$ The study included 267 patients with predominantly idiopathic PAH (79\%), and those with WHO FC II (26\%) and WHO FC III (66\%) symptoms. Addition of sildenafil was associated with a significant placebo-adjusted increase in 6MWD of $26 \mathrm{~m}(P=0.0009)$ and increased time to clinical worsening. Hemodynamic improvements were noted with addition of sildenafil, including a reduction in mPAP of $3.9 \mathrm{~mm} \mathrm{mg}$ $(P=0.00003)$. Health-related QoL was improved with sildenafil treatment, despite no significant changes in the Borg dyspnea score.

A few small single center studies have reported safety in adding sildenafil in combination with inhaled iloprost. The study with the longest follow up evaluated patients who experienced clinical worsening after treatment with iloprost. Fourteen patients were randomized to treatment with sildenafil or placebo, and the sildenafil-treated group experienced significant and durable improvements in 6MWD. ${ }^{46}$ The timing for introduction of a second agent remains unresolved. Based upon available literature, most therapies require 12 to 16 weeks for a maximal response. Additional improvements in exercise capacity as measured by 6MWD have not been demonstrated in nonblinded extension studies of the pivotal drug trials. Whether to initiate combination therapy prior to clinical deterioration in monotherapy, or earlier on in the course of disease, has not been established.

Coadministration of bosentan (a hepatic enzyme inducer) and sildenafil reduces plasma levels of sildenafil and increases bosentan concentrations, though the clinical significance of this remains uncertain. ${ }^{47}$ As described earlier, bosentan 
induces expression of CYP2C9 and CYP3A4, which are involved with metabolism of sildenafil, and can decrease the pharmaceutical area under the curve by approximately $55 \% .{ }^{47}$ To determine if any clinically relevant interaction existed, the COMPASS I study investigated the acute hemodynamic effects of sildenafil addition to patients on long-term bosentan therapy. ${ }^{48}$ Sildenafil administration reduced PVR by $15 \%$, comparable to that seen with sildenafil montherapy in treatment-naïve patients. Despite the pharmacokinetic interaction between the agents, most experts believe that alterations in treatment effects of either drug are not apparent with the combination, and dose adjustment are usually not required. There are no clinically relevant interactions between ambrisentan and sildenafil. ${ }^{49}$

Broad treatment guidelines apply to all patients with PAH. Hypoxemia is a potent pulmonary vasoconstrictor, and it is advisable for oxygen to be administered to maintain saturations above 90\%. Right heart failure and symptoms of congestion are common, and therapy with diuretics is often required to maintain an optimal volume state. Calcium channel blocker use should be restricted to patients with WHO FC I-III patients with idiopathic PAH who demonstrate a positive response to a vasodilator challenge at the time of right heart catheterization. A positive response is defined as a decline in the mean pulmonary artery pressure of $>10 \mathrm{mmHg}$ and to a level less than $40 \mathrm{mmHg}$, with an unchanged or improved cardiac index. Oral digoxin has not been studied in a controlled fashion, but in patients with advanced disease exhibiting signs and symptoms of RV failure, or those with atrial tachyarrhythmias who may not tolerate beta blockers, therapy with digoxin may be beneficial. In patients with IPAH, anticoagulation with coumadin is recommended in absence of contraindications.

\section{Costs of PAH therapy}

Society is becoming increasingly aware of the costs of health care. Of the nine FDA-approved therapies, only epoprostenol is available in the generic from. Compared to drugs routinely used to treat common cardiopulmonary conditions (hypertension, dyslipidemia, obstructive lung disease) PAH pharmacotherapy is considerably more costly. Uninsured or underinsured patients will be unable to afford the costs of PAH pharmacotherapy in the absence of other financial support. It is therefore incumbent upon the physician to perform a thorough diagnostic evaluation to confirm the diagnosis of $\mathrm{PAH}$, and exclude more common conditions, including obstructive lung disease, obstructive sleep apnea, and pulmonary venous hypertension from systolic or diastolic dysfunction. A recent study examined the costs of PAH pharmacotherapy. The investigators obtained cost information from US medicare and medicaid data, and utilizing a Markov-type model, determined that in medically comparable patients, treatment with sildenafil was less costly and associated with a net increase in quality adjusted lifeyears. ${ }^{50}$ In insured patients who have adequate prescription drug coverage, we feel that the factors described previously, and not the cost of therapy, should drive decisions on pharmacotherapy.

\section{Other PDE-5 inhibitors}

Tadalafil is an orally administered PDE-5 inhibitor currently approved for treatment erectile dysfunction and $\mathrm{PAH}$. A 16-week randomized, placebo-controlled study comparing tadalafil at doses ranging from $2.5 \mathrm{mg}$ to $40 \mathrm{mg}$ to placebo in patients with $\mathrm{PAH}$ was recently published. ${ }^{51}$ Similar to the SUPER-1 Study, the primary endpoint in this trial was change in functional capacity as estimated by 6MWD. The mean placebo-corrected improvement in 6MWD was $33 \mathrm{~m}$. When patients on background therapy with bosentan were removed, and only PAH treatment-naïve patients analyzed, the treatment effect was $44 \mathrm{~m}$, comparable to that noted with sildenafil in the SUPER-1 study. Additionally, the drug improved QoL, and was associated with comparable improvements in hemodynamic patterns. Tadalafil levels are reduced with coadministration with bosentan, ${ }^{52}$ and the FDA-approved dose of tadalafil is $40 \mathrm{mg}$ daily. Vardenafil is a commercially available PDE-5 inhibitor used for the treatment of erectile dysfunction that is not FDA approved for the treatment of PAH.

\section{Non-WHO group- I pulmonary hypertension}

Multiple conditions result in development of pulmonary hypertension, but are not characterized as PAH (Table 3). Phase III clinical trials have excluded these patients, and therefore, sildenafil is not FDA approved for treatment in these conditions. Smaller studies have suggested potential utility in several populations. In patients with chronic thromboembolic pulmonary hypertension (CTEPH), where anatomy is not favorable for surgical pulmonary arterial thromboendarterectomy, a potential beneficial effect to longterm sildenafil treatment has been suggested. ${ }^{53}$ Sildenafil may have a useful role in management of post-heart transplant $\mathrm{RV}$ dysfunction and to expedite weaning from inotropes. ${ }^{54}$ A small single-center study investigated high-dose sildenafil treatment in patients with pulmonary sarcoidosis (WHO 
Table 3 WHO classification of pulmonary hypertension

\begin{tabular}{ll}
\hline WHO classification & Disease states \\
\hline Group I: PAH & $\begin{array}{l}\text { Idiopathic PAH, familial PAH, } \\
\text { associated PAH } \\
\text { Valvular heart disease, systolic }\end{array}$ \\
Group II: Pulmonary hypertension & or diastolic dysfunction \\
with left heart disease & OSA, ILD, COPD, chronic \\
Group III: Pulmonary hypertension & hypoxemia \\
associated with lung disease or & \\
hypoxemia & Thromboembolic occlusion \\
Group IV: CTEPH & of the distal or proximal \\
& pulmonary vasculature \\
Group V: Miscellaneous & Sarcoidosis, fibrosing \\
& mediastinitis \\
\hline
\end{tabular}

Adapted from McLaughlin et al. ${ }^{42}$

Abbreviations: PAH, pulmonary arterial hypertension; OSA, obstructive sleep apnea; ILD, interstitial lung disease; COPD, chronic obstructive pulmonary disease; $\mathrm{CTEPH}$, chronic thromboembolic pulmonary hypertension.

Group V PH) where sildenafil treatment was associated with reductions in PA pressures, PVR, and improved cardiac index, but no change in 6MWD. ${ }^{55}$ In chronic obstructive pulmonary disease, single-dose treatment with sildenafil has been shown to reduce PA pressure, irrespective of baseline, but have no impact on cardiac output, stroke volume, or exercise capacity. ${ }^{56}$ In patients at high altitudes who are continuously exposed to hypoxic conditions, sildenafil has demonstrated beneficial effects in reducing PA pressures. ${ }^{57}$ In one study of patients with pulmonary fibrosis, sildenafil usage at $50 \mathrm{mg}$ daily reduced pulmonary vascular resistance, improved V/Q mismatch, and increased partial pressure of oxygen. ${ }^{58}$ In patients with systemic sclerosis, sildenafil treatment in patient with refractory Raynaud's with digital ulcers was associated with reduced frequency and duration of Raynaud's attacks, and improved capillary flow. ${ }^{59}$ Despite these promising initial data, larger clinical trials, with better delineation of the target populations and study endpoints, are warranted. Given the costs, unproven benefits, and potential side effects of therapy, it is generally not advisable to use sildenafil for conditions other than WHO Group I PH.

\section{Sildenafil in heart failure}

The most common cause of right heart failure is longstanding left heart failure and development of pulmonary venous hypertension. Over time, if left untreated, some patients can develop structural changes in the pulmonary arteries with resultant increase in pulmonary vascular resistance. ${ }^{60}$ Sildenafil has been shown to be well tolerated among severe end-stage heart failure patients undergoing transplant evaluation and as an acute screening agent for fixed pulmonary hypertension that would otherwise be a contraindication to heart transplantation. ${ }^{61}$ Impaired NO generation and utilization contributes to the abnormal cardiovascular phenotype in congestive heart failure. Based upon these observations, sildenafil is receiving increasing attention from the heart failure community.

From a historical perspective, PDE inhibitors were used with great caution in heart failure, because the PDE-3 inhibitor milrinone, which increases myocellular cyclic adenosine monophosphate (cAMP) levels, is associated with increased mortality in heart failure. ${ }^{62}$ However, sildenafil, through its high specificity for PDE-5, is believed to be far safer in this regard. From a safety standpoint, sildenafil has been studied in doses ranging from 25 to $100 \mathrm{mg}$ in patients with erectile dysfunction and heart failure and appears to be safe and well tolerated. ${ }^{61}$

Melonovsky et al studied the acute hemodynamic effects of sildenafil administration in heart failure. ${ }^{63}$ Following dosing with $40 \mathrm{mg}$ sildenafil, reductions in PVR and improvements in PA compliance were noted. Increased intracellular levels of cGMP were reported, suggesting that PDE5 inhibition restores sensitivity of pulmonary vascular to endogenous cGMP-dependent vasodilators. Additional studies of patients with heart failure and pulmonary hypertension demonstrated that sildenafil treatment was associated with improved ventilator efficiency, as determined by $\mathrm{Ve} / \mathrm{VCO}_{2}$ slope by cardiopulmonary stress testing, and correlated with drops in pulmonary vascular resistance and improvement in RV ejection fraction. ${ }^{64}$ Sildenafil may improve RV systolic function in patients with heart failure complicated by $\mathrm{PH}^{64}$ A small, placebo-controlled randomized study in congestive heart failure patients demonstrated that 4 weeks of sildenafil administration improved functional capacity, ventilator efficiency, and pulmonary hypertension. ${ }^{65}$ In stable heart failure patients, sildenafil treatment improves $\mathrm{mVO}_{2}$ max and improves endothelial function as measured by brachial artery flow-mediated dilation, suggesting endothelium-mediated attenuation of exercising muscle oversignaling. ${ }^{66}$ Nitrates are commonly used in heart failure, and are contraindicated with sildenafil administration. However, a small study demonstrated safety and efficacy of combing nitrates with sildenafil to further reduce PA pressures in advanced heart failure ${ }^{67}$ Taken together, the experience of sildenafil in heart failure appears promising and provocative, and a potential novel application.

\section{Conclusions}

Sildenafil has emerged as a safe and efficacious pharmacotherapy for PAH. Longer-term studies, examining the effects 
of therapy on disease remodeling overall survival have yet to be completed. Combination therapy is an exciting development in the treatment of PAH. A favorable side effect profile and acceptable dosing regimen make sildenafil an attractive option for combination therapy, and studies are underway examining multiple drug combinations. By enhancing downstream effects of NO, there is potential for sildenafil to have utility in treating various conditions with endothelial dysfunction and regional alterations in blood flow.

\section{Disclosures}

Gautam Ramani has served as a consultant to United Therapeutics, Actelion, and Gilead. Myung Park has served as a consultant to United Therapeutics, Actelion, Gilead and Pfizer.

\section{References}

1. Humbert M, Sibton O, Chaout A, et al. Pulmonary arterial hypertension in France: Results from a national registry. Am J Respir Crit Care Med. 2006;173:1023-1026.

2. Butrous G, Ghofrani HA, Grimminger F. Pulmonary vascular diseases in the developing world. Circulation. 2008;118:1758-1766.

3. D'Alonzo GE, Barst RJ, Ayres SM, et al. Survival in patients with primary pulmonary hypertension: results from a national prospective registry. Ann Intern Med. 1991;115:343-349.

4. McLaughlin VV, Sibton O, Badesch DB, et al. Survival with first-line bosentan in patients with primary pulmonary hypertension. Eur Respir J. 2005;25:244-249. Erratum in Eur Respir J. 2005;25:942.

5. Michelakis ED, Wilkins MR, Rabinovitch M. Emerging concepts and translational priorities in pulmonary arterial hypertension. Circulation. 2008;118:1486-1495.

6. Archer SL, Michelakis ED. Phosphodiesterase type 5 Inhibitors for pulmonary arterial hypertension. N Engl J Med. 2009;361:1864-1861.

7. Goldstein I, Lue TF, Padma-Nathan H, et al. Oral sildenafil in the treatment of erectile dysfunction. N Engl J Med. 1998;338:1397-1404.

8. Galie N, et al. Sildenafil citrate therapy for pulmonary arterial hypertension. N Engl J Med. 2005;353:2148-2157.

9. Lucas KA, Pitari GM, Kazerounian S, et al. Guanyl cyclases and signaling by cyclic GMP. Pharmacol Rev. 2000;52:375-413.

10. Moncada S, Palmer RM, Higgs EA. Nitric oxide: physiology, pathophysiology and pharmacology. Pharmacol Rev. 1991;43:109-142.

11. Tantini B, Manes A, Fiumana E, et al. Antiproliferative effect of sildenafil on human pulmonary artery smooth muscle cells. Basic Res Cardiol. 2005;100:131-138.

12. Girgis RE, Champion HC, Diette GB, et al. Decreased exhaled nitric oxide in pulmonary arterial hypertension: response to bosentan therapy. Am J Respir Crit Care Med. 2005;172:352-357.

13. Beall CM, Laskowski D, Strohl KP, et al. Pulmonary nitric oxide in mountain dwellers. Nature. 2001;414:411-412.

14. Wang C, Wang J, Zhao L, et al. Sildenafil inhibits human pulmonary artery smooth muscle cell proliferation by decreasing capacitative $\mathrm{Ca}^{2+}$ entry. J Pharmacol Sci. 2008;108:71-78.

15. Francis SH, Corbin JD. Sildenafil: efficacy, safety, tolerability and mechanism of action in treating erectile dysfunction. Expert Opin Drug Metab Toxicol. 2005;1:283-293.

16. Wharton J, et al. Antiproliferative effects of phosphodiesterase type 5 inhibition in human pulmonary artery cells. Am J Respir Crit Care Med. 2005;172:105-113.

17. Corbin JD, Beasley A, Blount MA, et al. High lung PDE5: a strong basis for treating pulmonary hypertension with PDE5 inhibitors. Biochem Biophys Res Commun. 2005;334:930-938.
18. Haynes J, Kithas PA, Taylor AE, et al. Selective inhibition of cGMPinhibitable cAMP phosphodiesterase decreases pulmonary vasoreactivity. Am J Physiol. 1991;261:H487-H492.

19. Zhao L, et al. Sildenafil inhibits hypoxia-induced pulmonary hypertension. Circulation. 2001;104:424-429.

20. Kosmicki MA. Long-term use of short and long-acting nitrates in stable angina pectoris. Curr Clin Pharmacol. 2009;4:132-141.

21. Abdollahi M, Fooladian F, Emani B, et al. Protection by sildenafil and theophylline of lead acetate-induced oxidative stress in rat submandibular gland and saliva. Hum Exp Toxicol. 2003;22:587-592.

22. Perk H, Armagan A, Naziroglu M, et al. Sildenafil citrate as a phosphodiesterase inhibitor has an antioxidant effect in the blood of men. $J$ Clin Pharm Ther. 2008;33:635-640.

23. Nagendran J, Archer SL, Soliman D, et al. Phosphodiesterase type 5 is highly expressed in the hypertrophied human right ventricle, and acute inhibition of phosphodiesterase type 5 improves contractility. Circulation. 2007;116:238-248.

24. Michelakis E, Tymchak W, Lien D, et al. Oral sildenafil is an effective and specific pulmonary vasodilator in patients with pulmonary arterial hypertension: comparison with inhaled nitric oxide. Circulation. 2002;105:2398-2403.

25. Lepore JJ, Maroo A, Bigatello LM, et al. Hemodynamic effects of sildenafil in patients with congestive heart failure and pulmonary hypertension: combined administration with inhaled nitric oxide. Chest. 2005;127:1647-1653.

26. Diller GP, van Eijl S, Okonko Do, et al. Circulation endothelial progenitor cells in patients with Eisenmenger syndrome and idiopathic pulmonary arterial hypertension. Circulation. 2008;117:3020-3030.

27. Schermuly RT, Pullamsetti SS, Kwapiszewska G, et al. Phosphodiesterase 1 upregulation in pulmonary arterial hypertension: target for reverse-remodeling therapy. Circulation. 2007;115:2331-2339.

28. Nichols DJ, Muirhead GJ, Harness JA. Pharmacokinetics of sildenafil after single oral doses in healthy male subjects: absolute bioavailability, food effects and dose proportionality. Br J Clin Pharmacol. 2002;53 Supp1 1:5S-12S.

29. Muirhead GJ, Wilner K, Colburn W, et al. The effects of age and renal and hepatic impairment on the pharmacokinetics of sildenafil. Br J Clin Pharmacol. 2002;53 Suppl 1:21S-30S.

30. Revatio.com [Home page on the internet] Updated 11/2009. http://www. revatio.com/intermediateLaunch.aspx Accessed 12/27/2009. Accessed Dec 2009.

31. Huang S, Hermes DeSantis, Evelyn R. Treatment of pulmonary arterial hypertension in pregnancy. Am J Health Syst Pharm. 2007;64: 1922-1926.

32. Webb DJ, Freestone S, Allen MJ. Sildenafil citrate and blood-pressurelowering drugs: results of drug interaction studies with an organic nitrate and a calcium antagonist. Am J Cardiol. 1999;83:21C-28C.

33. Webb DJ, Muirhead GJ, Wulff M, et al. Sildenafil citrate potentiates the hypotensive effects of nitric oxide donor drugs in male patients with stable angina. J Am Coll Cardiol. 2000;36:25-31.

34. Jackson G, Benjamin N, Jackson N, et al. Effects of sildenafil citrate on human hemodynamics. Am J Cardiol. 1999;83:13C-20C.

35. Laties AM. Vision disorders and phosphodiesterase type 5 inhibitors: a review of the evidence to date. Drug Saf. 2009;32:1-18.

36. Philip A, Ramachandani S, Dorrance K, et al. Sildenafil-induced thrombocytopenia. Ann Intern Med. 2008;149:437-439.

37. Prasad S, Wilkinson J, Gatzoulis MA. Sildenafil in primary pulmonary hypertension. $N$ Engl J Med. 2000;343:1342.

38. Atz AM, Wessel DL. Sildenafil ameliorates effects of inhaled nitric oxide withdrawal. Anesthesiology. 1999;91:307-310.

39. Sastry BK, Narasimhan C, Reddy NK, et al. Clinical efficacy of sildenafil in primary pulmonary hypertension: a randomized, placebo-controlled, double-blind, crossover study. J Am Coll Cardiol. 2004;43:1149-1153.

40. Badesch DB, Hill NS, Burgess G, et al. Sildenafil for pulmonary arterial hypertension associated with connective tissue disease. J Rheumatol. 2007;34:2417-2422. 
41. Michelakis ED, Tymchak W, Noga M, et al. Long-term treatment with oral sildenafil is safe and improves functional capacity and hemodynamics in patients with pulmonary arterial hypertension. Circulation. 2003;108:2066-2069.

42. McLaughlin VV, Archer SL, Badesch DB, et al. ACCF/AHA 2009 expert consensus document on pulmonary hypertension: a report of the American College of Cardiology Foundation Task Force on Expert Consensus Documents and the American Heart Association developed in collaboration with the American College of Chest Physicians; American Thoracic Society, Inc.; and the Pulmonary Hypertension Association. J Am Coll Cardiol. 2009;53:1573-1619.

43. Wilkins MR, Paul GA, Strange JW, et al. Sildenafil versus Endothelin Receptor Antagonist for Pulmonary Hypertension (SERAPH) Study. Am J Respir Crit Care Med. 2005;171:1292-1297.

44. Hemmes AR, Robbins IM. Sildenafil monotherapy in portopulmonary hypertension can facilitate liver transplantation. Liver Transpl. 2009;15:15-19.

45. Simonneau G, Rubin LJ, Galie N, et al. Addition of sildenafil to longterm intravenous Epoprostenol therapy in patients with pulmonary arterial hypertension. Ann Intern Med. 2008;149:521-530.

46. Ghofrani HA, Rose F, Schermuly RT, et al. Oral sildenafil as longterm adjunct therapy to inhaled iloprost in severe pulmonary arterial hypertension. J Am Coll Cardiol. 2003;42:158-164.

47. Burgess G, Hoogkamer H, Collings L, et al. Mutual pharmacokinetic interactions between steady-state bosentan and sildenafil. Eur J Clin Pharmacol. 2008;64:43-50.

48. Gruenig E, Michelakis E, Vachiery JL, et al. Acute hemodynamic effects of single-dose sildenafil when added to established bosentan therapy in patients with pulmonary arterial hypertension: results of the COMPASS-1 study. J Clin Pharmacol. 2009;49:1343-1352.

49. Spence R, Mandagere A, Dufton C, et al. Pharmacokinetics and safety of ambrisentan in combination with sildenafil in healthy volunteers. J Clin Pharmacol. 2008;48:1451-1459.

50. Gann MC, Clark L, Chumney EC, et al. Cost-utility of treatment for pulmonary arterial hypertension: a Markov state-transition decision analysis model. Clin Drug Investig. 2009;29:635-646.

51. Galie N, Bundage BH, Ghofrani HA, et al. Tadalafil therapy for pulmonary arterial hypertension. Circulation. 2009;119:2894-2903.

52. Wrishko RE, Dingemanse J, Yu A, et al. Pharmacokinetic interaction between tadalafil and bosentan in healthy male subjects. J Clin Pharmacol. 2008;48:610-618.

53. Reichenberger F, et al. Long-term treatment with sildenafil in chronic thromboembolic pulmonary hypertension. Eur Respir J. 2007;30:922-927.

54. DeSanto LS, Mastroianni C, Romano G, et al. Role of sildenafil in acute posttransplant right ventricular dysfunction: successful experience in 13 consecutive patients. Transplant Proc. 2008;40:2015-2018.

55. Milman N, Burton CM, Iversen M, et al. Pulmonary hypertension in end stage pulmonary sarcoidosis: therapeutic effect of sildenafil? J Heart Lung Transplant. 2008;27:329-334.
56. Holverda S, Rietema H, Bogaard HJ, et al. Acute effects of sildenafil on exercise pulmonary hemodynamics and capacity in patients with COPD. Pulm Pharmacol Ther. 2008;21:558-564.

57. Richalet JP, Gratadour P, Robach P, et al. Sildenafil inhibits altitudeinduced hypoxemia and pulmonary hypertension. Am J Respir Crit Care Med. 2005;171:275-281.

58. Ghofrani HA, Wiedemann R, Rose F, et al. Sildenafil for treatment of lung fibrosis and pulmonary hypertension: a randomized controlled trial. Lancet. 2002;360:895-900.

59. Fries R, Shariat K, von Wilmowsky H, et al. Sildenafil in the treatment of Raynaud's phenomenon resistant to vasodilatory therapy. Circulation. 2005;112:2980-2985

60. Hoeper MM, Barbera JA, Channick RN, et al. Diagnosis, assessment, and treatment of non-pulmonary arterial hypertension pulmonary hypertension. J Am Coll Cardiol. 2009;54:S85-S96.

61. Katz SD, Parker JD, Glasser DB, et al. Efficacy and safety of sildenafil citrate in men with erectile dysfunction and chronic heart failure. Am J Cardiol. 2005;95:36-42.

62. Packer M, Carver JR, Rodeheffer RJ, et al; for the PROMISE study research group. Effect of oral milrinone on mortality in severe chronic heart failure. N Engl J Med. 1991;325:1468-1475.

63. Melenovsky V, Al-Hiti H, Kazdova L, et al. Transpulmonary B-type natriuretic peptide uptake and cyclic guanosine monophosphate release in heart failure and pulmonary hypertension: the effects of sildenafil. J Am Coll Cardiol. 2009;54:595-600.

64. Lewis GD, Shah RV, Pappagianopolas PP, et al. Determinants of ventilator efficiency in heart failure: the role of right ventricular performance and pulmonary vascular tone. Circ Heart Fail. 2008;1:227-233.

65. Behling A, Rohde LE, Colombo FC, et al. Effect of 5'-phosphodiesterase four-week long inhibition with sildenafil in patients with chronic heart failure: a double-blind placebo-controlled clinical trial. J Card Fail. 2008;14:189-197.

66. Guazzi M, Samaja M, Arena R, et al. Long-term use of sildenafil in the therapeutic management of heart failure. J Am Coll Cardiol. 2007;50:2136-2144.

67. Stehlik J, Movsesian MA. Combined use of PDE5 inhibitors and nitrates in the treatment of pulmonary arterial hypertension patients with heart failure. J Card Fail. 2009;15:31-34.

68. Humbert M, Sitbon O, Simonneau G. Treatment of pulmonary arterial hypertension. N Engl J Med. 2004;351:1425-1436.

69. Barst RJ, editor. Pulmonary Arterial Hypertension: Diagnosis and Evidence-Based Treatment. West Sussex, England. John Wiley \& Sons; 2008.

70. McLaughlin VV, McGoon MD. Pulmonary arterial hypertension. Circulation. 2006;114:1417-1431.
Drug Design, Development and Therapy

\section{Publish your work in this journal}

Drug Design, Development and Therapy is an international, peerreviewed open-access journal that spans the spectrum of drug design and development through to clinical applications. Clinical outcomes, patient safety, and programs for the development and effective, safe, and sustained use of medicines are a feature of the journal, which

\section{Dovepress}

has also been accepted for indexing on PubMed Central. The manuscript management system is completely online and includes a very quick and fair peer-review system, which is all easy to use. Visit http://www.dovepress.com/testimonials.php to read real quotes from published authors. 